\title{
Chapter 4 \\ The Spatial Variants and Temporal \\ Sequence of the Indigenous Cultural \\ System of Southeast China During \\ Neolithic, Bronze, and Early Iron Ages
}

The archaeological cultures from Neolithic Age to early Iron Age in the Southeast of China including south of Jiangsu (江苏) and Anhui (安徽), Zhejiang (浙江), Jiangxi (江西), southeast of Hunan (湖南), Fujian (福建), Guangdong (广东), Guangxi (广西), Hainan (海南), Taiwan (台湾) and the adjacent coast of Vietnam, compose one of the special segment in the unity of "Assimilation and Integration of Pluralistic Cultures" in prehistoric and early history of China. These regional cultures with the continuingly temporal sequence have developed for thousands of years from early Neolithic Age to early Iron Age, "Relying on Huaxia Nationality of Central Nation and Facing Maritime Barbarians of Austronesian", are just the material cultural heritages of the indigenous Miao, Man, Bai Yue and their ancestors in the "Southeastern Direction" of the ancient Chinese history. The archaeological investigations on these indigenous cultural heritages in southeast China from Neolithic to early Iron Age, mainly focused on the evolution of the spatial and temporal types of material cultures characterized by stepped stone adzes, shouldered stone axes and adzes, and stamped pattern potteries, providing an empirical basis for understanding the prehistoric and early cultural distribution and evolution, as well as ethnic group migration, North-South or Center-Periphery interaction, and cultural assimilation between Huaxia nationality in North and indigenous Miao, Man and Bai Yue ethnicities in South (Lin, H.X. 1936, 1937, 1938, 1958a, b; Lv, R. F. 1959; Li, B.Q. 1981; CREC 1981; Peng, S.F. 1987; Wu, C.M. 1999c: 62-81). Among these spatial and temporal distributions of different cultures of Neolithic, Bronze, and early Iron ages in the "Southeastern Direction" of China, there had no parallel interregional relationship, but a complicated echelon order of different regions, respectively presenting differentiated interactions with the Central Nation of ancient Chinese civilization, while relying on Huaxia nationality or facing maritime "Barbarians". These differentiated levels of cultural distributions were mainly constrained by the Wuyi (武夷)-Nanling (南岭) mountainous watershed and the segmentation of oceans, resulting distinctly the regional differences between the inner and outer of mountain, between the land and sea, with different cultural 
connotations and sociocultural and economic development, forming a spatial layout with three regions distribution pattern (Wu, C.M. 1999c: 62-73).

1. The plain region with lakes and rivers lying to the south of the lower Yangtze River, and beyond the west and north of Wuyi-Nanling watershed, centering on the Taihu (太湖) Lake and Poyang (鄱阳) Lake Basins, as the north part of the "Southeastern Direction", relied on Huaxia nationality and territorially connected to the Central Plains in the middle and lower reaches of the Yellow River. The prehistoric and early cultures in this plain region were more influenced and assimilated by the "Central" Huaxia and Han (汉) cultural system of the North and their sociocultural development had almost synchronized with that of the "Center" of early civilization of ancient China.

2. The mountainous region along the coast beyond east and south of Wuyi-Nanling watershed, covering from the south of Zhejiang to Fujian, Guangdong, and Guangxi, located far away from the Huaxia nationality of Central Nation, and faced and connected with the maritime "Barbarians" on islands in the south sea. Though the prehistoric and early cultures of these areas were also influenced and infiltrated indirectly by the cultures of Huaxia system from the Central Plains, for a long period of time they developed relatively in the enclosed or semi-enclosed geographical and cultural environment. The prehistoric and early cultures relatively stagnated, the social complexity and early civilization receded far behind the north "Center", until the early Iron Age when these indigenous cultures were assimilated by the southward immigrating Huaxia, Chu (楚) and Han nationalities.

3. The island region of Taiwan, Hainan, and other oceanic areas, where indigenous cultures developed independently, were far beyond the range of cultural influence of the Central Plains, and the social cultures stagnated for a long period until the late and modern periods.

The feature of this differentiated echelon order of the spatial distribution of archaeological cultures with three regions and multi-districts in the "Southeastern Direction" of China, reveals geopolitical layout of the indigenous Miao, Man and Bai Yue, as well as their interaction and assimilation in varying degrees with the cultures in Central Nation and north of China (Fig. 4.1; Table 4.1).

\subsection{Relying on the Huaxia Nationality: The Cultural Assimilation Within the Plain Region Lying to the South of the Yangtze River}

According to the researches on the spatial-temporal typology of the prehistoric cultures, the plain region with the lakes and rivers lying to the south of the Yangtze River, centering on Taihu and Poyang lake basins, was mainly composed of several ancient cultural districts, such as Ningzhen (宁镇)-Wannan (皖南) District coving 


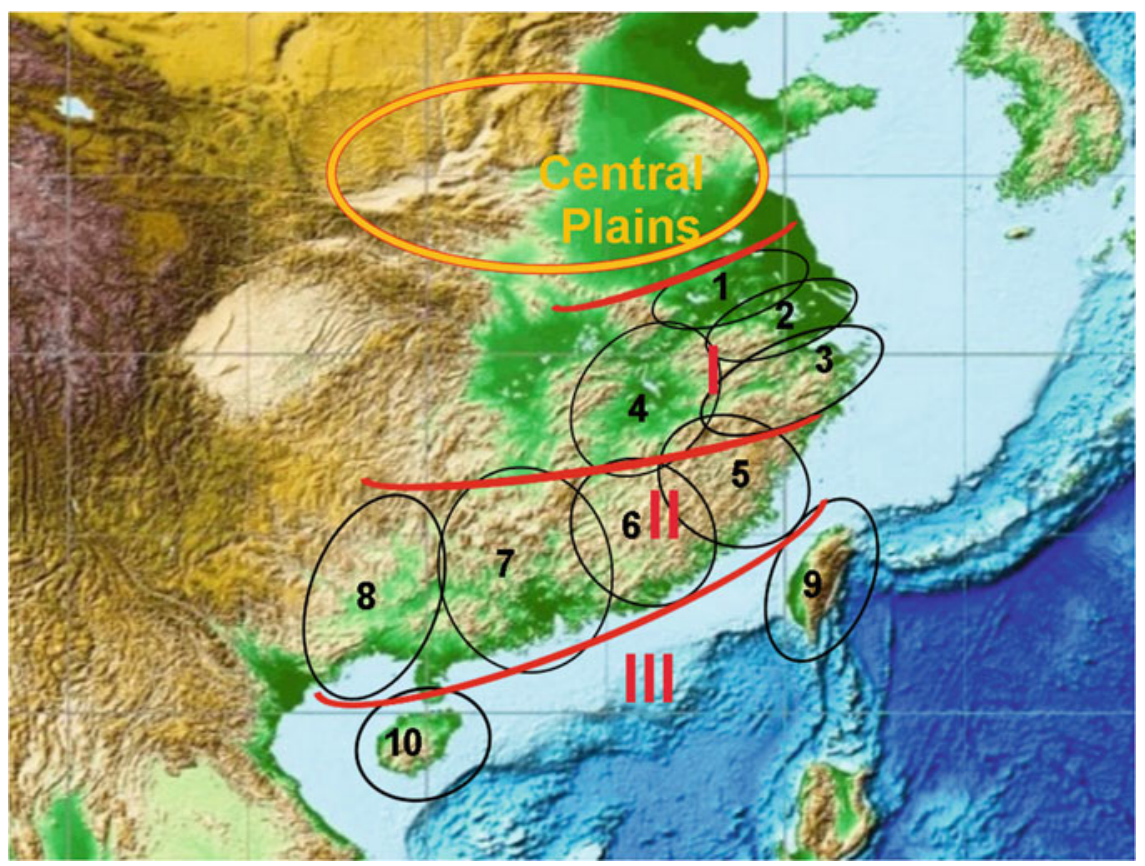

Fig. 4.1 Spatial distribution of archaeological cultures in the "Southeastern Direction" of China. I. Plain region lying to south of the lower Yangtze River, II. Coastal region beyond east and south of Wuyi-Nanling mountains, III. Island region of Taiwan and Hainan (1. Ningzhen-Wannan, 2. Taihu Lake Basin, 3. Ningbo-Shaoxing Plain, 4. Ganpo Basin in Jiangxi, 5. Minjiang River Basin, 6. Eastern Guangdong to Southern Fujian, 7. Pearl River Basin, 8. Xijiang River Basin, 9. Taiwan Island, 10. Hainan Island)

Nanjing (南京), Zhenjiang (镇江) and southern Anhui, Taihu Lake Basin in south of Jiangsu and Shanghai, Ningbo-Shaoxing (宁绍) Plain covering the south coast of Qiantangjiang (钱塘江) River in Zhejiang Province and Ganpo (赣鄱) Basin in Jiangxi Province. Among them, the area between southern Jiangsu and northern Zhejiang where Ningzhen-Wannan, Taihu Lake Basin, and Ningbo-Shaoxing Plain situate, formed a relatively independent sub-regional culture unity according to their more similarity of material cultural remains, stood in parallel with another sub-region Ganpo Basin, embodied the multi-level spatial interaction among the prehistoric and early cultures in this north part of "Southeastern Direction" of China.

This region was the original land of the prehistoric ancestors of Gou Wu (句吴), $Y u$ Yue (于越), Gan Yue (干越) and Yang Yue (扬越), being contiguous to the territory of Central Plains and the North of China, and relying on Huaxia and Han cultural system. From the Neolithic to Early Iron ages, its cultural connotations accepted much more influences of the North than other regions and districts in southeast coast of China did. The Neolithic indigenous people developed the earliest cultivated rice of the world, and then initiated one of the earliest states or chiefdoms of ancient civilization in southeast of China, establishing one of the 
Table 4.1 The spatial and temporal cultures of Neolithic, bronze, and early iron age in the southeast of China

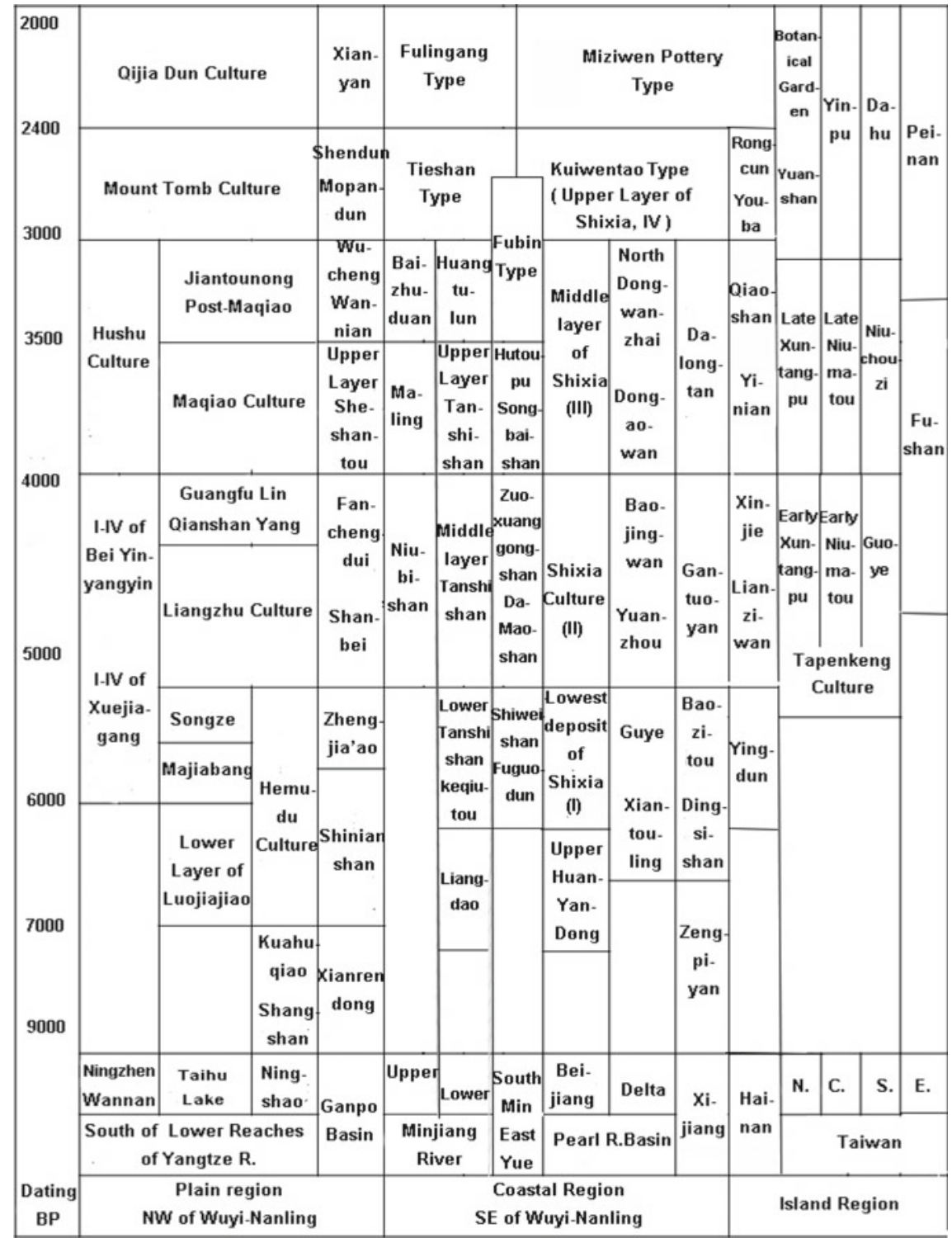


centers of the pluralistic origin of Chinese civilization in the Longshan (龙山) era. Its sociocultural development almost synchronized with the Central Plains and North of China, and once even "Competing for Controlling of the Central Plains" (逐鹿中原) during the Three Dynasties of early Chinese civilization.

\subsubsection{Temporal Sequence of the Indigenous Cultures and Northern Influences in Neolithic Age}

The Taihu Lake Basin as cultural center of northern part of plain region lying to the south of Yangtze River, where the other two cultural districts as Ningzhen-Wannan and Ningbo-Shaoxing Plain also situate, witnessed to the successively developing Neolithic cultures of Lower Layer Type of Luojiajiao (罗家角) (7000-6400 BP), Majiabang (马家浜) Type (6400-6000 BP), Songze (崧泽) Type (6000-5300BP), Liangzhu (良渚) Culture (5300-4200 BP), Qianshanyang (钱山漾) and Guangfulin (广富林) Culture (4200-3900 BP), and alike (Mou, Y.K. et al. 1980; Ji, Z.Q. 1984; Huang, X.P. et al. 1981; Song, J. 2014a, b; Chen, J. 2014). The Ningzhen area adjacent to Taihu Lake Basin appeared the cultures of the first to fourth phases (6400-4000 BP) of the Bei Yinyangying (北阴阳营) Culture, and the Wannan area presented the remains of the first to fourth phases (6400-4000 BP) of the lower layer of Xuejiagang (薛家岗) Culture (Yang, D.B. 1984; Jiang, Z.C. 1981). In the Ningbo-Shaoxing Plain and the coast of Qiantangjiang River, there were Shangshan (上山) Culture (10000-8500 BP), Kuahuqiao (跨湖桥) Culture (8000-7000 BP), Hemudu (河姆渡) Culture (7000-5300 BP), and the local type of Liangzhu Culture (5300-4000 BP), forming its own Neolithic sequence (Mou, Y.K. 1981, 1984; Liu, J. 1984; Sun, H.L. et al. 2019a, b).

The Neolithic cultures in the region were distinctively characterized by a compound of two types of material cultural elements, namely the "Southeast" indigenous elements represented by the round bottom and ring foot pottery wares, and a lot of external elements from the Central Plains and "North" represented by tripod and pouch or hollow-leg pottery wares which had originally been the cultural features of the lower reaches Yellow River since the early Neolithic age. Nevertheless, in the different sub-districts and their different temporal stages, the southward cultural influences and assimilation were not completely consistent, and the sociocultural evolution of them did not synchronize, presenting the spatial-temporal variants from the north to south and from the early to late periods.

On the one hand, the typical indigenous pottery wares of Luojiajiao, Majiabang, and Songze cultures were the round bottoms $F u$ (釜) cauldrons with a waist edge or multi angle edge, the round bottom or small flat bottom pots, bowls, plates and kettles, trumpet-shaped or tower-shaped ring foot dou (豆) plates, short ring foot or petal-shaped ring foot kettles and cups, and cooking pot supports. This set of pottery utensils basically represented the indigenous cultural connotation of north part of "Southeast" during pre-Longshannian period. 
On the other hand, the influence of tripod and pouch-shaped leg vessels of pottery, which were the typical characteristics of Neolithic cultures of the Beixin (北辛), Dawenkou (大汶口) and Longshan centering in the lower reaches of the Yellow River, varied in different times and spaces. These external influences decreased from north to south and increased along with the development from early to late stages. And in the same cultural period or stage, there were significantly more tripod and pouch-shaped leg vessels in the north sub-districts than that in the south. Specifically, the cultures of Luojiajiao and Majiabang in the Taihu Lake Basin had only a few flat chisel-shaped tripods Ding (鼎) vessels, while in stage of Songze Type the Ding vessels increased and varied with the types of tripod as chisel-shaped, flat lateral-shaped, and bow back-shaped, and the types of Ding body as $F u$ pot-shaped, jar-shaped, and basin-shaped, resulting from being reinforced influences of Dawenkou Culture of the North. More direct evidence of this kind of influence can also be seen in Bei Yinyangying Culture in Ningzhen area. In the Ningbo-Shaoxing Plain, being located in the much more southward than Taihu Lake Basin, the round bottom and ring foot pottery vessels and cooking vessel supports were remarkably the majority of the indigenous pottery group in the first to fourth stages of Hemudu Culture, and the external tripod pottery vessels were rarely seen (Fig. 4.2).
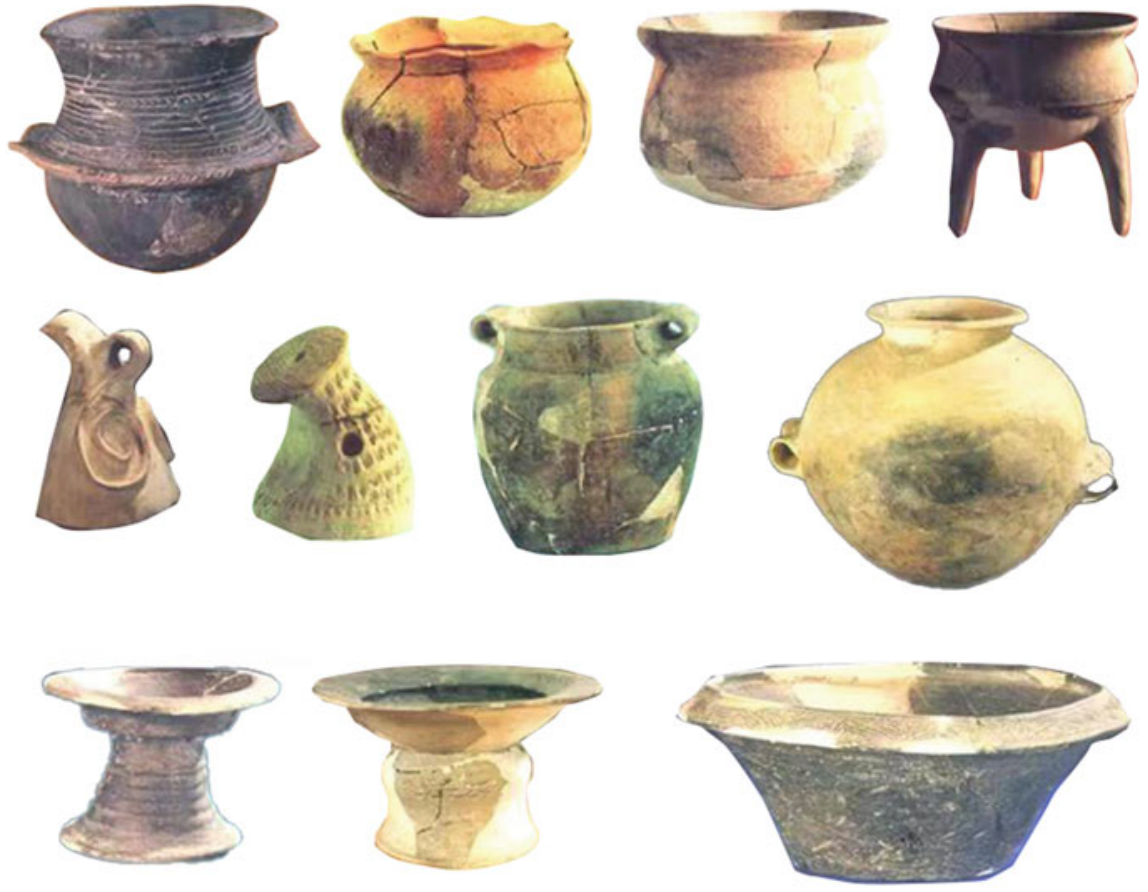

Fig. 4.2 The pottery content of Neolithic Hemudu Culture 
At the stage of Liangzhu Culture, the tripods vessels of the northern influences in the Taihu Lake Basin began to be as developed as the native ring foot vessels, while the round bottom vessels became rare, but the large or short ring foot kettles, pots, Gui (笽) bowl, large basin could be evidently identified as being originated from the artifacts of local combination of Songze Type. There appeared more different forms of tripod Ding vessel showing the increase of the northern influences. Of course, not all of them were the direct influences from the typical Longshan Culture, for example, the fish fin-shaped leg of the tripods was developed from the flat lateral leg in the Songze stage. However, the common appearance of polished black pottery and the large pouch-shaped leg Gui (哣) kettle were the product of the direct influence of Longshan Culture of Shandong region. By comparing, we also can see that the types in the southern marginal area of Liangzhu Culture, the remains in Mingshanhou (名山后) in Fenghua (奉化) county in Ningbo-Shaoxing plain, were much less influenced by the North culture (MSAT 1993). More round bottom and small flat bottom $F u$ cauldrons, pots, high and low ring foot pottery vessels were unearthed with fish fin-shaped tripods and conical-shaped tripod vessels.

In the Ganpo Basin district of the southern part of the plain region, covering the Ganjiang (赣江) River and Poyang Lake Basin, Neolithic cultures varied chronologically with Xianrendong (仙人洞) Culture (9000-7000 BP) in early stage, Shinianshan (拾年山) Culture (7000-5000 BP) in middle stage, Shanbei-Fanchengdui (山背-樊城堆) Culture (5000-4000 BP) in late stage, the upper layer type of Sheshantou (社山头) Culture (4000-3500 BP) in the latest stage and so on (Li, J.H. et al. 1986a, 1989; Peng, S.F. 1986; Liu, S.Z 1993; Wu, C.M. 1999c: 83-96). Its latest limit of Neolithic culture receded some more than that of Taihu Lake Basin and Ningbo-Shaoxing Plain, while the cultural connotations had similar compound of those two types. In the Xianrendong and first stage of Shinianshan Culture, the native round bottom, flat bottom $F u$ cauldrons, pots, bowls were the basic forms of utensil pottery, no external tripod vessels developed. During Zhengjia'ao (郑家坳) and the second stage of Shinianshan Culture, more tripods such as Ding vessels with $F u$ cauldron, jar or bowl-shaped belly with flat lateral foot, tube foot, or conical-shaped tripods, solid tripod Gui (鬶) kettles were unearthed with the original local forms of round bottom, flat bottom $F u$ cauldrons, pots, bowls, and trumpet-shaped and tower-shaped ring foot Dou plates, short ring foot Gui (笽) bowl and kettles and other vessels. The emergence of these tripod vessels was related to the strong influence from Dawenkou Culture of the lower reaches of Yellow River which dispersing southward via Yangtze-Huaihe rivers (江 淮) basin. These external influences had been assimilated with the indigenous culture, for example, the various tripod Ding vessels were generally formed by adding tripods on the local indigenous round bottom vessels of $F u$ cauldrons, and even the unique local and mixed varieties of tube foot tripod vessels appeared. At the late stage as Shanbei-Fanchengdui Culture, the "North" elements increased much more than the earlier stage, such as the newly appeared T-shaped, fish fin-shaped, tile-shaped leg of tripod pottery Ding vessels and even the pouch-shaped leg Gui (鬶) and $\mathrm{He}$ (盉) kettles. There were also some elements similar to the Qujialing (屈家岭) Culture from the middle reaches of the Yangtze 
River, showing the diverse and complex situation of external influences impacted on Neolithic Ganpo Basin.

\subsubsection{The North-South Cultural Assimilation During the Bronze and the Early Iron Age}

The material cultures of Bronze and early Iron Age in the plain region lying to the south of the Yangtze River belonged to the typical stamped pattern pottery cultural system. Along with the gradual and differentiated influence of northern cultural elements in the Neolithic Age, the indigenous stamped pattern pottery cultures were more deeply influenced by the bronze culture of Xia, Shang, and Zhou dynasties.

The compound of indigenous culture with northern Xia and Shang bronze cultures were distinctive in the stamped pattern pottery remains of Hushu (湖熟) Culture (4000-3000 BP), Maqiao (马桥) Culture (3900-3000 BP) and Wucheng (吴城) Culture (3500-3000 BP) distributing from north to south in the plain region lying to the south Yangtze river (Ji, Z.Q. 1981; Huang, X.P. et al. 1981; Liu, J.G. et al. 1989; Mou, Y.K. 1993; Song, J. 2014b). In the Hushu Culture, large amount of low tripod Ding with pot-shaped belly, pouch-shaped leg double bellies Yan (戲) boilers and the pouch-shaped leg $l i$ (鬲) cookers as characteristic elements of Xia and Shang cultures were unearthed together with small flat bottom or round bottom urns, pots, Zun (尊) pots, basins, bowls, ring foot Dou plates and Gui (策) bowls of the indigenous cultural system. In Maqiao Culture and Jiantounong (肩头弄) Culture, the indigenous connotation as the round bottom, concaved-round bottom, and small flat bottom $F u$ cauldrons, bowls, pots, $Y u$ (孟) pots, and cups, as well as double bellies boilers Yan and ring foot Dou plates, Gui (笪) bowls, kettles, Zun pots were quite popular, while tripod cauldron-shaped belly Ding cooking vessels and a small number of pouch-shaped leg Yan boiling cookers and $\mathrm{He}$ kettles were also unearthed. No pouch-shaped leg $l i$ cookers were found. Moreover, because of the geographical location, the influence of the Xia and Shang cultures in the plain region of southern Jiangsu and northern Zhejiang, represented by the pouch-shaped leg Gui (鬶) kettles, He kettles, and $l i$ cookers, also gradually decreased from the north to south.

In the Wucheng Culture in Ganpo Basin, the indigenous elements presented round bottom, concaved-round bottom, small flat bottom, and ring foot wares of pottery, including the main forms as $F u$ cauldrons, various pots, urns, $Y u$ pots, bowls, Yan boilers, Dou plates and alike, while the external cultural elements included pottery wares of Shang culture such as pouch-shaped leg $l i$ cooker and Yan boilers, tripod cooking vessels Jia (牟), large rim Zun pots, abdomen-shaped ring foot Dou plates, long belly pots, as well as bronze ritual vessels and weapons of Shang culture, such as tripod Ding cooking vessels, pouch-shaped leg Yan boilers, 
tripod cooking vessels Jia, knives, dagger-axe, and alike. The indigenous elements represented by the pottery artifacts were the mainstream of the Wucheng Culture, but the bronze artifacts mainly belonged to the category of external Shang Culture. The bronze wares discovered in Dayangzhou (大洋洲) site of Xinggan (新干) county had the similar compound with Wucheng (Li, J.H. et al. 1986b, 1989; Peng, S.F. 1986; Li, B.Q. 1981; Peng, S.F.et al. 1993).

During the Zhou Dynasty, the bronze cultures in this region were unified in the system of archaeological Mound Tomb (土墩墓) Culture (3000-2400 BP). The burial custom of it was regionally distinctive, with burial artifacts of stamped geometric pattern pottery and glazed pottery pots, short jars Tan (坛), $B u$ (鶕) pots, $F u$ cauldrons, as well as glazed pottery ring foot $D o u$ plates, bowls, basins, plates, and alike, representing the main trend of the indigenous culture, while the corded pattern pottery of the tripod Ding cooking vessels, three hollow pouch-shaped leg $l i$ cookers and Yan boilers, as well as the bronze ritual vessels such as tripod Ding cooking vessels, pouch-shaped leg $l i$ cooker, ring foot Gui (篮) bowls, Zun pots, $Y o u$ (备) wine pots and plates, representing the external influences from northern Shang and Zhou cultures (Zou, H.B. 1982; Liu, J.G. et al. 1989). Shendun (神墩) and Mopandun (磨盘墩) types (3000-2400 BP), which were in the sub-regional type of Mound Tomb Culture in Ganpo Basin, also manifested the compound of the similar two types (Li, J.H. et al. 1986b, 1989; Peng, S.F. 1986). The indigenous stamped geometric pattern pottery and glazed pottery Yan boilers, $F u$ cauldrons, pots with round bottom or round concave bottom, Dou plates, $G u i$ (笽) bowls, $Y u$ pots with ring foot were unearthed together with three pouch-shaped leg pottery $l i$ cookers and Yan boilers, long necked pottery Zun pots, as well as bronze ritual vessels and weapons that representing the northern cultural elements of Shang and Zhou dynasties.

In the early Iron Age, Qijiadun (戚家墩) Culture ( 2400-2000 BP) developed on the basis of the native Mound Tomb Culture in southern Jiangsu and northern Zhejiang, and the indigenous culture was more comprehensively assimilated by the Chu and Han cultures (Jiang, Z.C. 1981; Huang, X.P. et al. 1981). In early typical remains of this type, the lower layer of Qijiadun Culture and upper layer of Maqiao Culture in Shanghai, the indigenous feature represented by stamped pattern pottery jars, pots, cups, and primitive porcelain bowls, cups remained the main trend of the cultural compound. In the late typical remains, the Lizhu (漓渚) and Fenghuangshan (凤凰山) cemeteries in Shaoxing (绍兴) of Zhejiang, the indigenous primitive porcelain and stamped pattern pottery reduced significantly, while the glazed tripod Ding cooking vessels, boxes, and kettles as the bronze ritual wares imitators representing $\mathrm{Chu}$ and Han style vessels gradually became the mainstream. In the Xianyan (仙岩) Type (2400-2000 BP) in Ganpo Basin in the Eastern Zhou Dynasty, a large number of $\mathrm{Chu}$ and Han style utensils such as imitated bronze wares of pottery tripod Ding cooking vessels and handled $\mathrm{He}$ wine kettles were also unearthed together with the native stamped pattern pottery wares (Li, J.H. et al. 1986b, 1989; Peng, S.F. 1986). 


\subsubsection{Growing to Compete with Huaxia for Controlling the Central Plains}

From Neolithic to Early Iron ages, the indigenous cultures in the plain region lying to the south of the Yangtze River were influenced and assimilated deeply by the prehistoric and early cultures of the Central Plains in the North. The process of social complication and civilization of this region also synchronized that of Huaxia, and was one of the most developed and advanced regions in the indigenous cultural system in the "Southeastern Direction" of China. The region had been one of the earliest origins of cultivated rice in East Asia for thousands of years, establishing the mature rice farming societies in the early and middle stages of Neolithic cultures such as Luojiajiao, Majiabang, and Hemudu. During the period of Liangzhu Culture, the early chiefdom state society formed, being represented archaeologically by the settlement pattern of centralized city ruin, large tombs with jade burials and ancestor worship altar remains. Liangzhu Culture might have been the first social-political entity of the early civilization in the southeast of China, and one of the several central areas in Longshan era "Competing for Controlling of the Central Plains", which promoted the rising of Chinese civilization (Yan, W.M. 1993, 1996; $\mathrm{Su}$, B.Q. 1996). Although the bronze culture in this plain region was generally receding to the Central Plain of north China, it simultaneously emerged and developed. In the Xia and Shang dynasties, a small amount of bronze ware appeared in Maqiao and Hushu cultures, and Wucheng Culture was one of the important bronze cultural centers in Shang Dynasty. The bronze cultures of this region progressed continuingly during the West and East Zhou dynasties, dispersed across the Wuyi-Nanling mountain watershed, and influenced the southeast coast region in Fujian and Guangdong.

In short, an important feature of the cultural development from Neolithic to Early Iron ages in the plain region with lakes and rivers lying to the south of the Yangtze River, was the direct influence and assimilation of the Central Plain and North cultures from the middle and lower reaches of the Yellow River. These influences manifested in a spatial-temporal process that gradually strengthened from the south to north, and maintained a comprehensive and sustained impact from Neolithic to Early Iron ages, until the Eastern Zhou, Qin, and Han dynasties when being unified into the Huaxia system. Although the development of its prehistoric and early social cultures was slightly different from North, it basically synchronized with that of the middle and lower reaches of the Yellow River as the "Center" of early civilization in China. 


\subsection{Facing the Islands $Y i$ in the South Sea: The Indigenous Cultural Communities in Mountainous Areas Along the Southeast Coast of China}

The prehistoric cultures from Neolithic to Early Iron ages in the coastal hilly and mountainous areas from southern Zhejiang to Fujian, Guangdong, and Guangxi, beyond the east and south Wuyi-Nanling mountain watershed, varied in a number of cultural districts as Minjiang (闽江) River Basin, Eastern Guangdong to Southern Fujian (粤东闽南), Pearl River Basin (珠江流域) and Xijiang (西江流 域) River Basin, where the aboriginal Min Yue, Eastern Ou (Yue), Southern Yue, West $\mathrm{Ou}$ and Luo Yue and their ancestors had lived. These cultural districts were far away from the Central Plain and the North, facing the maritime "barbarians" or Island $Y i$ and Austronesian in the South Sea. The separation by the Wuyi-Nanling mountain watershed made them stronger indigenous essence with enclosed or semi-enclosed developing patterns in prehistory and early history. Although the indigenous cultures of these districts were progressively infiltrated and influenced by Huaxia system from the Central Plain and North during Longshan era, Xia, and Shang dynasties, they persisted and developed their native essence for a long period of time until being fully assimilated by $\mathrm{Chu}$ and Han culture in the early Iron Age. The distinctively geographic and natural environment hindered the development of rice farming agriculture and the foraging pattern of gathering and hunting remained the important subsistence for a long period of time. The overall level of social development receded behind the plain region beyond the west and north of the Wuyi-Nanling mountain watershed, and the Central Plain in the North of China.

\subsubsection{Persisting of the Indigenous Tradition of Neolithic Cultures and the Infiltration of Northern Cultures}

The development of Neolithic cultures in hilly and mountainous coast beyond the east and south of Wuyi-Nanling watershed were receding far behind the plain region in north part of the "Southeastern Direction". The Neolithic stage lasted developing and no definite and objective evidences showed the development of bronze culture along this coastal region until Xia and Shang dynasties. Though the Longshan, Xia and Shang cultures of the North respectively influenced and infiltrated indirectly, partly, and intermittently across the mountain watershed to the coast region, the indigenous tradition represented by the material cultural features of round bottom and ring foot pottery vessels had always been the mainstream in the prehistoric and early cultures along the southeast coast. 


\subsubsection{Minjiang River Basin}

The prehistoric and early cultures of the Minjiang River basin developed and evolved with its center in the downstream area. After the earliest Liangdao (亮岛) in the Matzu (马祖) islands around the estuary of Minjiang River about 8000 years ago, the Neolithic cultures varied temporally with Keqiutou Type (壳丘头)-Lower Layer Type of Tanshishan (是石山 6000-5000 BP), Middle Layer Type of Tanshishan (5000-4000 BP), Upper Layer Type of Tanshishan-Huangtulun (黄土 仑) Type (4000-3000 BP). In the upper reaches of Minjiang River also existed the corresponding Neolithic Niubishan (牛鼻山) Type (5000-4000 BP), Maling (马岭) Type (4000-3500 BP) and Baizhuduan (白主段) Type (3500-3000 BP) (Wu, C.M. 1990a, b, 1995; Lin, G.W. 1990; Chen, C.Y. 2012; Chen, C.Y. et al. 2012).

The continuation and inheritance of indigenous Neolithic cultures in the lower reaches of Minjiang River and eastern coast of Fujian were most obviously reflected in the material cultures of pottery connotation (Wu, C.M. 1990a, 1995). As to the paste, coarse sandy pottery of Keqiutou, red pottery of Tanshishan lower layer, gray pottery of Tanshishan middle layer, orange pottery, and gray stoneware of Tanshishan upper layer, and gray stoneware of Huangtulun respectively represented the successive developing stages of Neolithic cultures in this area. Along these evolving stages, the gray pottery in the middle layer of Tanshishan originated from the red slipped gray pottery in the lower layer, and the gray stone ware in its upper layer originated from the high-fired gray fine pottery in its middle layer. As to the decoration patterns, the red slip and red painting lines pattern of the lower layer of Tanshishan was developed into the red painting stripes and round-dot patterns of its middle layer, and the characteristic black painting geometric lines and imitated bronze patterns were also the continuation and development of early color paintings. The stamped stripes pattern being simplified from the corded pattern of the lower type of Tanshishan, became the major decoration in its middle layer, while a small number of grids and check patterns evolving from crossed stripes of its middle layer became the source of representative pattern in its upper layer. The majority forms of pottery ware were round bottom $F u$ cauldrons, pots, kettles and ring foot pots, kettles, Gui (笽) bowls, cups, Dou plats and so on, forming a continued indigenous compound, together with a very small amount of pottery tripod Ding cooking vessels and no pouch-shaped leg vessels of North origin. The traditional cooking utensils of round bottom $F u$ cauldrons and pots with flared rim, accompanying various vessel supports, formed in the lower layer of Tanshishan and continued in the middle and upper layers. The Yan boilers with double cauldron-shaped belly of Huangtulun Type were also developed from the lower and middle layers of Tanshishan by heightening or widening the rim of $F u$ round bottom cauldrons, which were greatly different from the Neolithic pottery ware compound in Central Plain of tripod Ding cooker and pouch-shaped leg Yan, Li cookers and Gui (哣) kettles (Figs. 4.3, 4.4 and 4.5). Besides. The culture of the upstream of Minjiang River was basically consistent with the indigenous connotations in the lower reaches, with only slight differences. 


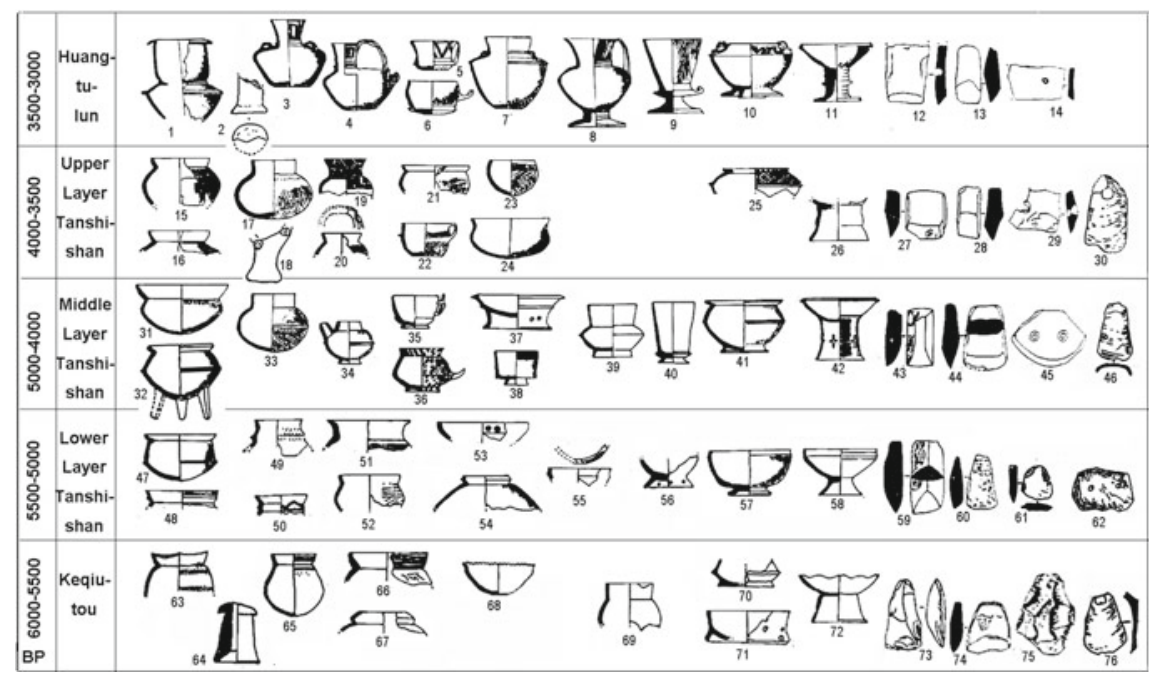

Fig. 4.3 The material cultural chronology in lower reaches of Minjiang River in the Neolithic Age (1, 3-11, Huangtulun; 2, 12-14, Fucun 浮村; 15, 17-20, 23-25, 27, 30, 32, 33, 36-39, 45-47, 49, 51-53, 55, 56, 59-62, Tanshishan; 16, 21, 26, 28, 28, 54, 57, 58, Zhuangbianshan 庄边山; 22, Dongzhang 东张; 31, 34, 35, 40-44, 48, 50, Xitou 溪头; 63-76, Keqiutou. 1-11, 15-26, 31-42, $47,58,63-72$, pottery wares; $12-14,27-29,43-45,59-61,73-75$, stone implements; 30, 46, 62, 76 , shell shovels)

Nevertheless, these Neolithic artifacts in the Minjiang River Basin, especially in its upstream, also showed some cultural influences from the North in varying degrees. The fine ground and perforated stone tools in the middle layer of Tanshishan, the stone knives, axes, shovels, sickles, gray and black pottery, as well as polished thin clay pottery, with a few of tripod Ding cooking vessels, He kettles, cups, and fitting handles and spouts, showed the cultural dissemination and influences from the Longshan of the North. The elements of cloud-thunder pattern, circular lines and wide folding shoulders, concaved-round bottom of the pottery wares in the upper layer of Tanshishan were the results of the dispersing and imitation of bronze cultures of Xia and Shang dynasties. The tiger-shapes kettle and Gui (鬶)-shaped kettles in Huangtulun were similar to those more commonly found in the plain regions of the north part of Southeast and the North of China in Shang Dynasty. Influenced by geographical location, there were more external cultural elements in the upper reaches of Minjiang River, for instance, more perforated stone axes, repeatedly perforated stone knives, various kinds of tripod pottery Ding cookers with shallow plate-shaped and basin-shaped bellies and tile-shaped, T-shaped, ghost mask-shaped, flat chisel-shaped legs, and pouch-shaped leg Gui (鬶) kettles were discovered. On the whole, however, these northern elements in the Minjiang River Basin still partly existed and were assimilated with local native tradition, for example, the very small amount of the tripod Ding cooking vessels in Tanshishan middle layer were made by adding three cylindrical legs on the body of 

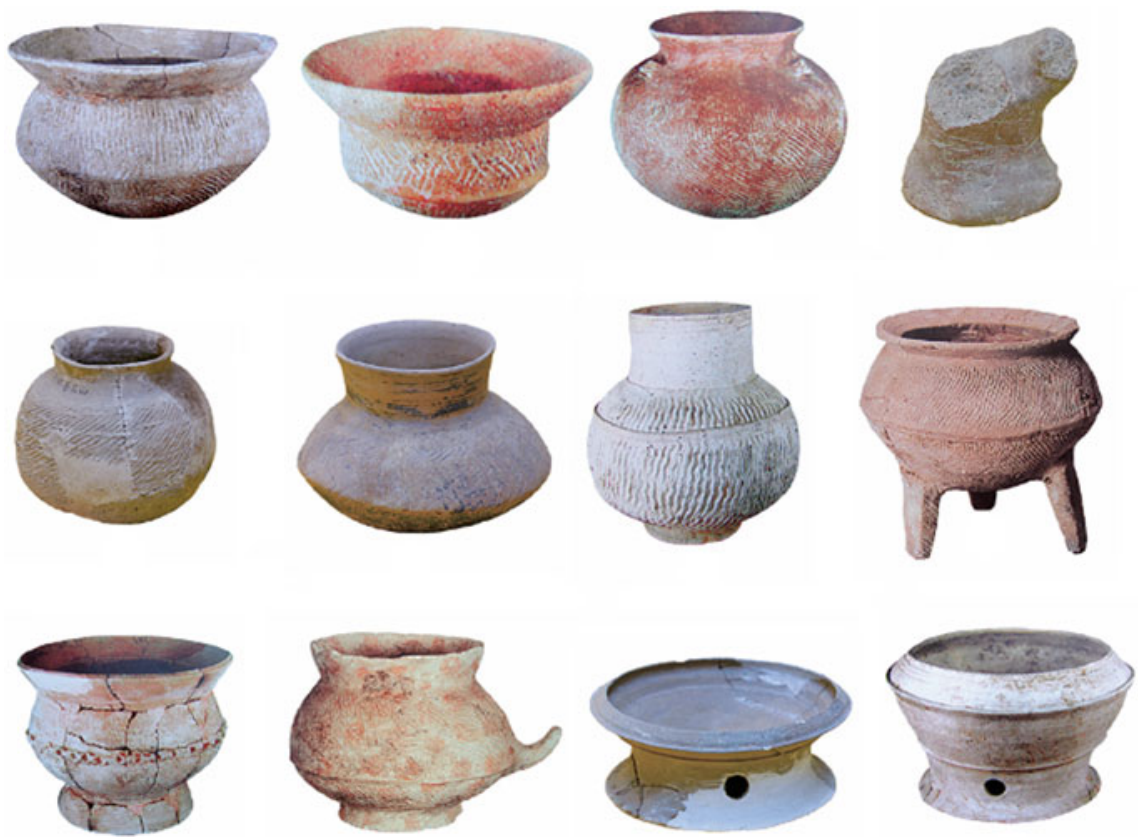

Fig. 4.4 The pottery wares of Tanshishan Culture
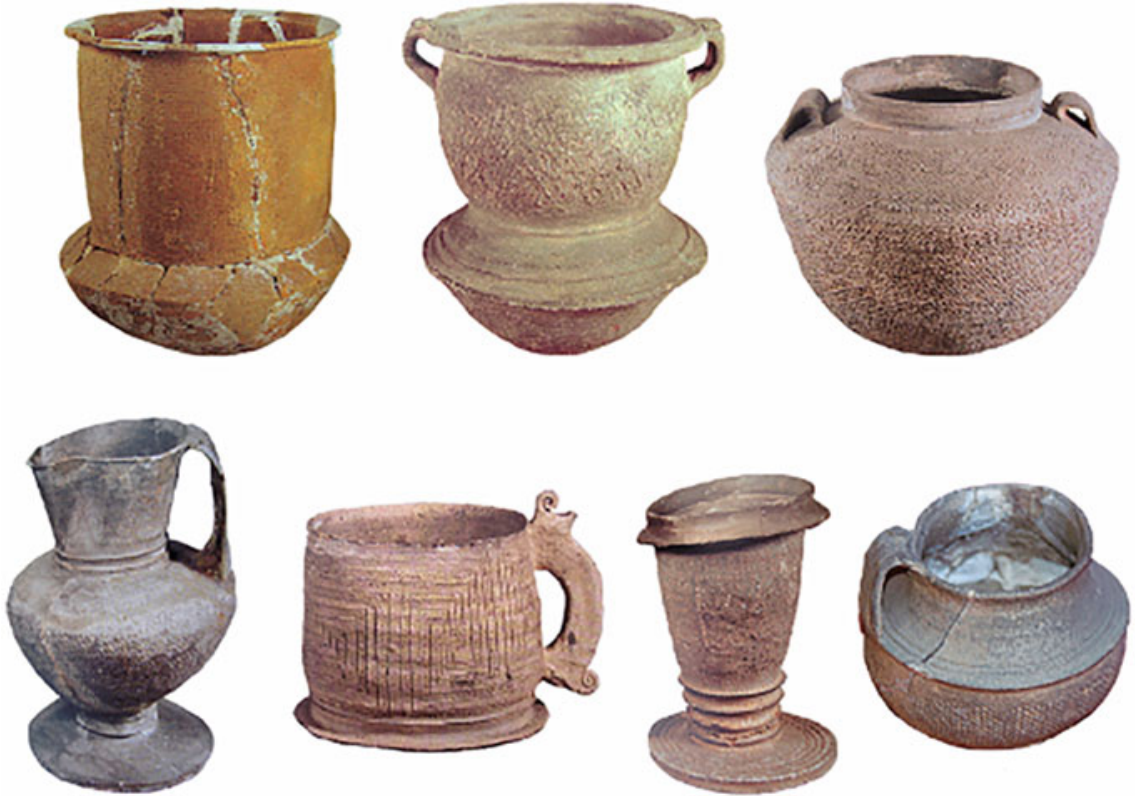

Fig. 4.5 The stamped pattern pottery connotation of Huangtulun Culture 
a local round bottom $F u$ cauldrons with flared rim and folded belly, and, the handled $\mathrm{He}$ kettles and pots were also made by adding a tubular spout and a horn like handle on the body of a local straight neck pot of flat bottom or short ring foot. So these small amounts of the external influences of Longshan, Xia and Shang cultures did not take over the mainstream of indigenous Neolithic culture.

\subsubsection{The Pearl River Basin}

The Neolithic cultures in the Pearl River Basin mainly included both the lowest deposit remain of Shixia (石峡) site (the First Stage) in Beijiang (北江) River basin of the upper reaches of Pearl River, and the Xiantouling (咸头岭)-Guye (古椰) cultures in the Pearl River Delta during the pre-Longshan era (7000-5000 BP), the Shixia (lower layer, the Second Stage) Culture-Shixia Middle Layer Type (the Third Stage) in Beijian, and the Baojingwan (宝镜湾) Type-Dong'ao'wan (东澳 湾) Type in the delta area, during the Longshan period to Xia and Shang dynasties (5000-3000 BP) (Zhu, F.S. et al. 1981; Zhu, F.S. 1984, 1991, 1994; Xu, H.B. 1981; Li, Z.W. 1991a; Li, Y. 1991, 2019; Tang, C. et al. 1991, 1994).

The material cultures of pre-Longshan era of the Pearl River Delta were mainly characterized by red-brown coarse sandy pottery wares with compound decoration of both stamped or shell incised cord, interlaced cord, row lines, comb dot, water wavy patterns, and colorfully painted band lines, dot, water wave lines, folded lines, S-shaped patterns. The basic combination of pottery forms were the round bottom $F u$ cauldrons or pots varying with shallow or deep bellies, bowls, and various kinds of ring foot plates, bowls, Dou plates and supports. Among them, the ring foot pottery plates with colorfully painted wave patterns were generally taken as similarity to the typical ring foot plates with the decoration patterns combined of carved, hollowed out, and painted of the Tahixi (大溪) Culture in the middle reaches of the Yangtze River. However, the characteristic connotation of painted wavy and S-shaped patterns should be closely related to marine landscape of the local coast region. Moreover, the distinctive characteristics of the cultures in this stage lacking the tripod pottery vessels, combining with cooking wares of wide rim, narrow neck, round bottom $F u$ cauldrons or pots and hollow supports, were basically different from those of the Neolithic cultures in the inner plain region beyond the north of Nanling mountain watershed in the earlier or the same period, with distinct indigenous identity (Wu, C.M. 1997a).

In the Pearl River Delta, the cultural influences from the North had gradually strengthened during the time of Longshan era, Xia and Shang dynasties. The pottery tripod Ding cooking vessel with tile-shaped legs or cylindrical legs unearthed in the sites of Yinzhou (银洲) of Sanshui (三水), Hudi (虎地) of Hong Kong was the result of the spreads and influences of the northern culture in the Longshan era, and high neck and folding shoulder pottery Zun pots, kettles, and pots with spouts, as well as the pottery wares with imitated bronze cloud-thunder pattern found in the North Dongwanzhai (东湾仔北) were also influenced by the 


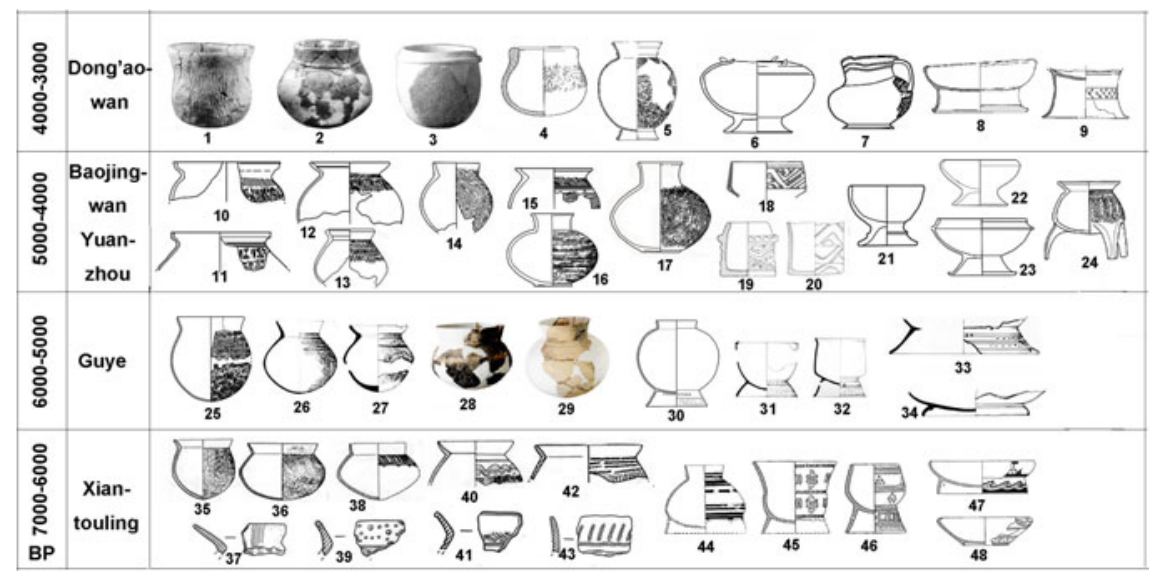

Fig. 4.6 The pottery ware sequence of Neolithic culture in Pearl River Delta (1-3, Dongwan 东湾; 4, 5, 8, 9, Cuntou 村头; 6, Hedan 河宕; 7, Yapowan 亚婆湾; 10, 16, 17, 21, Yuanzhou 圆洲; 11, 12, 14, 15, 22, Youyugang 鱿鱼岗; 13, 23, 24, Yinzhou 银洲; 18-20, Baojingwan 宝镜 湾; 25, 30, Shaxia 沙下; 26, 27, 31-34, Guoluwan 过路湾; 28, 29, Guye 古椰; 35-48, Xiantouling 咸头岭)

bronze culture of Central Plains and the North. However, the total amount of such external elements were limited, and the local pottery tradition of the compound of round bottom or concaved-round bottom $F u$ cauldrons, pots, kettles, bowls, ring foot $\mathrm{Dou}$ plates, pots, and plates formed since the pre-Longshan era basically remained, along with the periodically small changes in shapes and patterns. For example, the only tripod Ding cooker in the Yinzhou site was made by adding three tile-shaped legs on the locally typical flared rim, narrow neck, and round bottom pot shape cauldrons. The influence of bronze culture in Xia and Shang dynasties did not synchronously promote the formation and evolution of the Bronze culture in Pearl River Delta (Fig. 4.6).

In the Neolithic cultural connotation of the Beijiang River Basin, the characteristics of potteries in the Qingtang (青塘) cave and the lowest deposit remain of Shixia site were unified with the indigenous forms of the Pearl River Delta, manifesting the combination of the round bottom and ring foot vessels and the lacking tripod pottery wares. Nevertheless, obvious changes took place in the stage of Shixia Culture (tomb burial and the lower layer remains) in which two groups of elements of both native and external coexisted. One group was a continuation of the indigenous artifacts represented by the wide rim, narrow neck, round bottom pottery $F u$ cauldrons, pots, urns, and ring foot pots, plates, Dou plate. Another group was the dispersed cultures of the Zhuweicheng (筑卫城) and Fanchengdu from the Ganpo Basin beyond the north of Nanling mountain watershed in Longshan era, being represented by the tripod and pouch-shaped leg pottery vessels consisting of plate-shaped, basin-shaped, $F u$ cauldron-shaped bellies' Ding cooking vessels, tripod plates, and pouch-shaped leg Gui (鬶) kettles (Fig. 4.7). We believe that this 


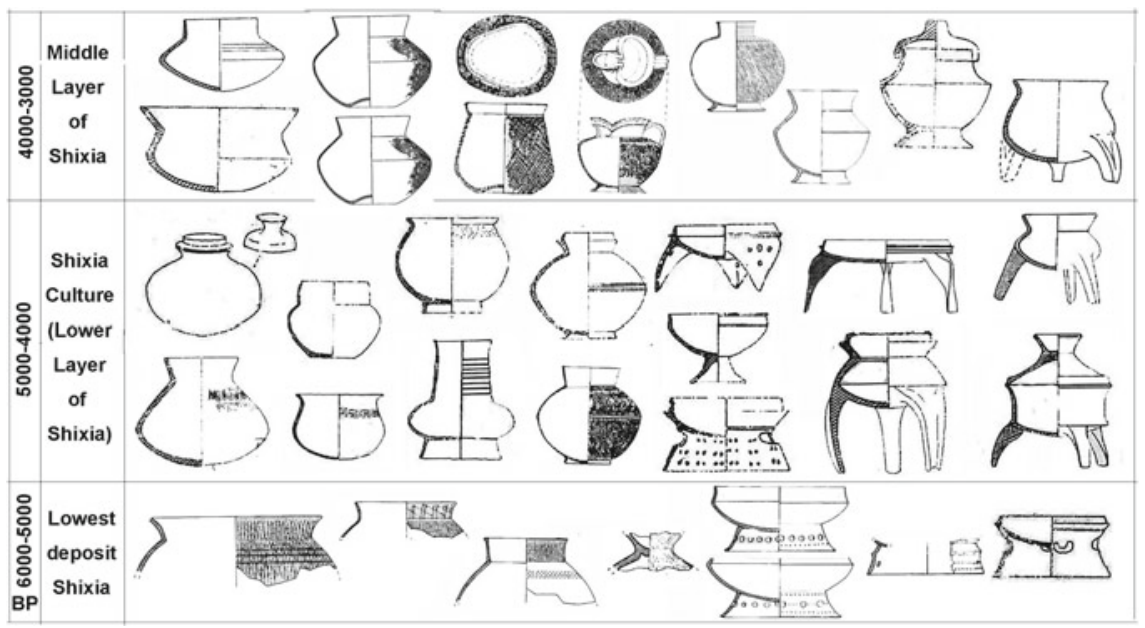

Fig. 4.7 The pottery ware sequence of Neolithic culture of Shixia site

group of external elements of Shixia Culture was not enough to constitute the basis of arguments of "southern distribution of the axis district along the Poyang Lake-Pearl River Delta", or the mixed "Fanchengdui-Shixia Culture" (Li, J.H. et al. 1989), which exaggerated the commonness of Longshannian cultures over the two sides of Nanling mountain watershed, and by no means to consider it as the evidence of "Sino-Tibetan Languages System" (Chang, K.C. 1989), which excessively regarded the coastal region of Longshannian Lingnan (岭南) as the immigrated culture of the Huaxia of North.

We found that the indigenous content of Shixia Culture generally remained as the majority, or core of the culture, and the external Longshannian elements from North were limited and being assimilated. For instance, the pot-shaped tripod Ding cooking vessels with the stretching legs, and the $F u$ cauldron-shaped belly tripod Ding cooking vessels were significantly different from the typical tripod Ding of Longshan Cultures beyond the north of Nanling watershed. More importantly, these external Longshan elements represented by various kinds of tripods and pouch-shaped leg vessels did not continue by the way of linking in the cultural series, but "disappeared" later in the Middle Layer Type of Shixia in the Xia and Shang dynasties, forming a false impression of "cultural fault" along the evolving series from the lower to the middle layers of the Shixia site. Nevertheless, the connotation in the middle layer of Shixia, represented by the combination of round or round concave bottom $F u$ cauldrons, pots, Zun kettles, bowls, ring foot jars, pots, and plates were actually the continuation of the main content of Lingnan indigenous culture originated from the lowest sediment remains of Shixia site, and the "interruption" from the North in the Longshan era, Xia and Shang dynasties was just the periodical elements of cultural influence (Yan, W.M. 1991). That is to say, the prominences of Neolithic culture in the Beijiang River Basin and the Pearl River 
Delta were the same as an unified indigenous culture. In the successive Neolithic cultural series composed of the lowest sediment remains of the Shixia site, the Shixia Culture, and the Middle Layer Type of Shixia, the indigenous cultural majority generally continued and inherited, the external elements in the Shixia Culture were only phased without profound influence and did not overturn the mainstream and core role of the indigenous cultural tradition.

\subsubsection{Eastern Guangdong and Southern Fujian}

The Neolithic cultures discovered in the Jinjiang (晋江), Jiulongjian (九龙江) and Hanjiang (韩江) river basins in eastern Guangdong and southern Fujian, includes the Shiweishan-Fuguodun (石尾山-富国墩) type (6000-5500 BP), Chenqiao-Lazhoushan (陈桥-腊洲山) type (5500-5000 BP) in early stage, the Zuoxuangongshan-Damaoshan (左宣恭山-大帽山) type (5000-4000 BP) in late stage, and the Hutoupu-Songbaishan (虎头埔-松柏山) type (4000-3500 BP) in the latest stage (GDPCRAC 1956; Lin, C.C. 1973; Xu, H.B. 1981; Zhu, F.S. 1984, 1986; Xu, Q.H. 1988; Wu, C.M. 1996b; Chen, C.Y. 1999; FJPM et al. 2003; Gan, X.L. 2010). The indigenous feature of Neolithic culture in this region was similar to that of Minjiang River Basin and Pearl River Basin, and the influences of external culture also appeared in Longshan era, Xia and Shang dynasties, mostly concentrating in the interior areas of the upper reaches of those rivers.

The main pottery content of the Longshan era unearthed at Zuoxuangongshan and Fenqikengshan (粪萁坑山) in Chaoyang (潮阳), Baotiandong (宝田岀) in Jieyang (揭阳), Damaoshan in Dongshan (东山) were sandy paste wares with stamped geometric patterns. The main types of vessels were round bottom $F u$ cauldrons, pots, ring foot pots, Dou plate, and vessels supports and alike, and most of the $F u$ cauldrons and pots were wide rim, narrow neck, round bottom, or ring foot, demonstrating the indigenous cultural traditions. The tripod Ding cooking vessels with $F u$ cauldron-shaped belly and square column, cylinder, tile-shaped or T-shaped legs unearthed at Baotiandong, and the pouch-shaped leg Gui (鬶) cooking vessels at Fenqikengshan were similar to that of Fanchengdui Culture in Ganpo Basin beyond the north of Nanling mountain, which was the result of the northern cultural influences of Longshan era.

Of the remains at Hutoupu and Chiwei Beishan (池尾北山) in Puning (普宁), Shuikoushan (水口山) in Pingyuan (平远), Yishan (蚁山) in Hui'an (惠安) and other cultural remains around the time of Xia and Shang dynasties, the basic type of pottery vessels still were the wide rim pots with globular belly and round bottom or round concave bottom, $Y u$ pots, basins, bowls, kettles with round bottom or flat bottom, and various kinds of vessel support, representing the composition of local features. The coexisting imitated bronze vessel patterns, the duck-shaped kettles with spout, and Zun pots with the high neck and folding shoulder were the external elements of Xia and Shang cultures. However, these external influences were quite limited and had not brought in the bronze culture to this coast region far away from the North, and the indigenous culture generally remained at the local Neolithic stage. 
On the whole, in the Neolithic cultures on the coastal region beyond the east and south of Wuyi-Nanling mountain watershed, the disseminations and influences of northern cultures generally scattered and partly existed, mainly concentrating in the upper reaches of Minjiang, Pearl (Beijiang) and Hanjiang rivers, and near the Wuyi-Nanling watershed. These external influences were phased and short lived, did not continue and profoundly extend to the whole territory of the hilly, coastal, indigenous region in "Southeastern Direction" of Central Nation, which is facing and territorially connecting to the "barbarians" Island $\mathrm{Yi}$ and Austronesian in the South Sea.

\subsubsection{The Bronze Cultural Dispersal of Zhou and Wu and the Evolution of Indigenous Society in Southeast Coast of China}

Since about 3000 years ago, in the time of West and East Zhou dynasties in the royal chronicles of Central Nation, there had been significant cultural changes in the indigenous region along the southeast coast of China, beyond the east and south of Wuyi-Nanling watershed. The Tieshan (铁山) Type (3000-2400 BP) in the Minjiang River Basin, the Fubin (浮滨) Type (3500-2500 BP) in eastern Guangdong and southern Fujian, and the Kuiwentao (㢡纹陶) Type or the Upper Layer Type of Shixia (the Fourth Stage, 3000-2400 BP) in Pearl River Basin, represented the main spatial types of the local bronze cultures formed by assimilation between the indigenous Neolithic cultures and external bronze cultures of the $W u$ and Yue from Taihu Lake Basin in the plain region of north part of southeast and the Shang and Zhou in the Central Plain (Wu, C.M. 1990a, 1994a, 1995, 1996b; Chen, C.X. et al. 1990; Xu, H.B. 1981, 1984; Zhu, F.S. 1978, 1986; Zhu, F.S. et al. 1981; He, J.S. 1981; GXZMCRAT 1981; Jiang, T.Y. et al. 1986; Gan, X.L. 2010).

The most obvious case of these mixed and assimilated bronze cultures in the southeast coast was the combination of two groups of cultural elements of Tieshan Type (TSHS et al. 1979; Wu, C.M. 1990a, 1994a, 1995; Chen, C.X. et al. 1990). The first group was the bronze cultural elements originated from Shang and Zhou cultures in the Central Plain, $W u$ and Yue states in the plain region of south Jiangsu and north Zhejiang. The representative bronze artifacts such as swords, spears, dagger-axes, axes, Nao (铙) bell, scrapers, chisels, and so on, were respectively identified as the imitation or diffusion of the external cultures of Shang and Zhou, and $W u$ and $Y u e$. The tomb remains of mounded stone and paved pebble structure, funeral objects such as stoneware urns, pots, bowls with mat patterns, primitive porcelain bowls, Dou plate and alike were also same as those of the Mound Tomb Culture of $W u$ and $Y u e$ in different stages. The second group was the continuance of indigenous cultural content since the Neolithic Age, including the typical pottery vessels of round bottom Yan boiler vessels with double cauldron-shaped belly, single handle pots, straight neck kettles, and other vessels which were identified as 


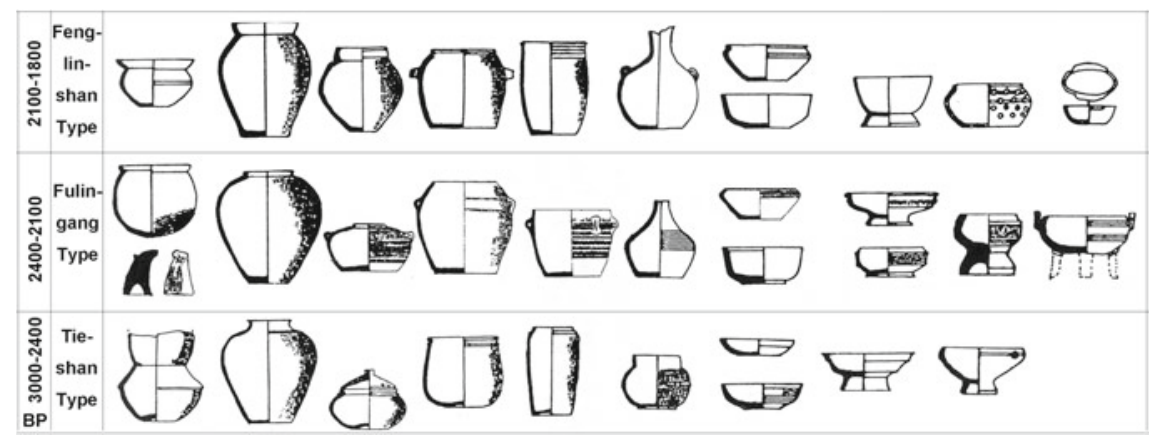

Fig. 4.8 The pottery ware sequence of Bronze and early Iron age in Minjiang River Basin

the inheritance and development of the native Neolithic cultural types of the middle and upper layer of Tanshishan and Huangtulun. Tieshan Type reflects the new stage of southward spreading of $W u$ and Yue cultures and its assimilation with the indigenous Neolithic cultures in the Minjiang River Basin (Fig. 4.8).

The Kuiwentao Type in Pearl River Basin also indicates the coexistence of external bronze cultural elements of Shang, Zhou, Wu and Yue, with the local indigenous cultural content. The external elements including bronze wine vessels as You, He, Lei (罍), and plates, musical instruments as Zhong (钟) bells and Nao bells, weapons as swords, dagger-axes and spears, were basically the same as those in the Shang and Zhou, as well as in $W u$ and Yue cultures. In addition, the primitive porcelain Dou plate and bowls in the upper layer of Shixia site were basically similar to those Mound Tomb Culture in the plain region beyond the north of Nanling mountain. However, the connotation of the Kuiwentao Type had strong indigenous characteristics, $W u$ and Yue cultural elements were less seen on most of its pottery artifacts than those on its bronze vessels. Many of the bronze vessels which originated from Shang and Zhou, as well as $W u$ and Yue cultures, also mixed with local features, such as bronze knives and other weapons unearthed in Yuanlongpo (元龙坡) cemetery in Wuming (武鸣), Guangxi. It can be seen that the Kuiwentao Type was a new stage of indigenous culture based on Neolithic culture in Pearl River Basin, under the cultural influence of the bronze civilization of Shang, Zhou, Wu and Yue (Xu, H.B. 1975, 1984; Zhu, F.S. 1978; He, J.S. 1981; Jiang, T.Y. et al. 1986; GXZMCRAT et al. 1988; Tang, C. 1993).

The external cultural elements in the connotation of Fubin Type were stone and bronze dagger-axes, bronze Ling (铃) bells, high neck, and folded shoulder pottery Zun pots, which had the characteristics of Xia, Shang, Wu and Yue cultures, and the glazed pottery cups with deeply folded belly and ring foot with the similar style of the Mound Tomb Culture. However, the Fubin Type lacked tripod and pouch-shaped leg pottery vessels of Xia, Shang and northern cultures and its general feature was the continuance of the Neolithic indigenous culture, including the typical objects such as concaved edge stone adzes, concaved edge bronze adzes, stepped bronze adzes, as well as the geometric pattern decorations as the checkered, 
zigzag, cloud-thunder, crossed lines on the bronze dagger-axes and Ling bell. These were distinctively the indigenous features and were identified their origins in the local Neolithic cultures (Zhuang, J.Q. et al. 1977; Yu, Y.R. 1978; Wu, C.M. 1990a, 1994a, 1996b).

Of all these districts in the southeast coast of China, it can be seen that their bronze cultures during the West and East Zhou dynasties shared common characters of both the continuance of the indigenous cultural tradition that originated in local Neolithic Age, and the dissemination and assimilation of the bronze cultures of Shang, Zhou, Wu and Yue beyond the north of Wuyi-Nanling mountain watershed. However, the introduction of these bronze cultures of Shang, Zhou, Wu and Yue haven't change the essential characteristics of indigenous culture represented by the compound of the stamped pattern pottery wares with round bottom and ring foot. These spatial types of mixed bronze cultures could be the archaeological relics of indigenous Min Yue, Southern Yue, Ou Yue, and so on, as variant branches of Bai Yue cultures, which formed by the assimilation of the Neolithic indigenous ancestors Min (闽), Yue (粤), Ou (瓯) and others with the external bronze cultures spreading southward from Shang, Zhou, Wu and Yue. With the influences of the external bronze cultures, the breaking of the enclosed or semi-enclosed pattern of indigenous culture, and the spreading of Shang, Zhou, Wu and Yue civilization, the civilized social systems of the Central Nation and $W u$, Yue states were also introduced and promoted the social complicating of this coastal region. For instance, a set of 12 pieces stone adze with echelon sizes and no mark of being used, was unearthed in Nan'an (南安) county of southern Fujian and identified as the special ritual vessels for the upper society of Fubin Type (Zhang, Z.C. et al. 1993; Wu, C. M. 1994). A lot of burials with funerary bronze weapons, or even the nice ritual bronze wares, such as $\mathrm{You}, \mathrm{He}$ and $\mathrm{Lei}$, and plates, were also identified as the remains of the tribal or military leaders in the upper class of local society. These discoveries with complicated elements of the civilized society reflect the origin indigenous state as the early stage of Min Yue, Ou Yue, Southern Yue, Western Ou, Luo Yue civilizations (Wu, C.M. 1990b, 1997b; Wu, C.M. et al. 2001).

\subsubsection{The Archaeological Remains of Sinicization of the Eastern Yue and Southern Yue in the Early Iron Age}

About two thousand four hundred years ago, during the end of Zhou, Qin, and Han dynasties in the empire chronicles of the Central Nation, the indigenous Bai Yue people on the southeast coast of China were conquered and their lands were annexed into the territory of the $C h u$, Qin and Han empires. More direct cultural interaction and assimilation of the early Iron Age occurred beyond the east and south of Wuyi-Nanling mountain watershed, pushing forward the evolution of the indigenous society and on the way of comprehensive Sinicization. 


\subsubsection{Min Yue or Eastern Yue Around Fujian Area}

The cultural connotations of Zhuangbianshan (庄边山) Type (2400-2200 BP) and Fulingang-Fenglinshan (富林岗一凤林山) types (2400-2000 BP) in Fujian region demonstrate the immigration of $\mathrm{Chu}$ and Han cultures to the southeast coast of China, and the Sinicization of indigenous Min Yue and Eastern Yue cultures (Wu, C.M. 1988, 1990a, 1995, 1999a; Wu, C.M. et al. 1998; Fig. 4.8).

The main burial objects unearthed from Zhuangbianshan tomb in Minhou (闽侯) county in the lower reaches of Minjiang River included pottery tripod Ding cooking vessels, boxes, Dou plates and kettles of the imitation of bronze ritual objects of Zhou Dynasty. However, most of these pottery vessels were not plain gray pottery of the Zhou and Han pattern but stoneware with stamped pattern of Yue style, and in particular, coexisting with the stamped pattern stoneware $B u$ pots, gourd-shaped kettles, and urns of typical Min Yue vessels. Therefore, the Zhuangbianshan Type was the remains of indigenized $C h u$ or Han cultures, showing that the immigrated $C h u$ or Han population were influenced by the local people and accepted the indigenous culture in the coastal area around Fujian (Wu, C.M. 1999a).

Fulingang Type of the end of Zhou, Qin, and early Han dynasties was the material cultural relics of the Min Yue and Eastern Yue, which were widely distributed around Fujian area. It contained not only the Han cultural elements such as bricks and tiles of Qin and Han style, seals and stamps with Chinese character, bronze and iron wares of the Zhou and Han cultures, pottery wares of Han cultures with the typical one of tripod pottery Ding cooker of imitated bronze ritual object, but also the connotation of local Yue culture as its main part. The stamped pattern pottery vessels composed of urns, pots, $B u$ pots, gourd-shaped kettles, bowls, $F u$ cauldrons and vessel supports, as well as indigenous piled-dwelling buildings, the tomb form with paved pebbles at bottom, most of which originated in the earlier bronze culture of Tieshan Type (Wu, C.M. 1988, 1999a).

The Fenglinshan Type of Eastern Han Dynasty changed greatly from its predecessor Fulingang Type. The indigenous pottery $F u$ cauldrons, urns, gourd-shaped kettles, pots, buckets, Bu pots, bowls, Dou plates with big ring foot and so on were the continuance of the similar vessels of the Fulingang Type, but the shapes of them changed respectively. The Han cultural elements of this type included the funerary object models of pottery barns, stoves, sacrificial utensils such as ears-shaped cups, incense burners, bronze coins of “Wuzhu” (五铢) and “Huoquan” (货泉) of Han Dynasties, and various kinds of Han style bronze and iron artifacts, indicating the stronger Sinicization of the local Min Yue culture after the indigenous state was perished (Wu, C.M. 1988; Wu, C.M. et al. 1998).

More than 100 brick tombs of the Six Dynasties have been found in Jianxi (建 溪) basin in upper reaches of Minjiang River, the coast areas of the lower reaches of Minjiang River, and lower reaches of Jinjiang River. The shape, structure, brick decoration patterns, and burial objects of these tombs were basically consistent with the connotation of the middle and lower reaches of the Yangtze and Yellow rivers, indicating that the immigrated Han people to the south and sinicized Min Yue 
indigenous people had become the main population around the Fujian area (Lin, Z G. et al. 1990).

\subsubsection{Southern Yue in Pearl River Basin}

The content of successively developing Miziwen Pottery (米字纹陶) Type and Checkered and Sealed Pattern Pottery (方格纹翟印陶) Type (2400-2000 BP) in Lingnan region of Pearl River Basin reflects the development of indigenous Southern Yue culture and its sinicization during the end of Zhou, Qin, and Han dynasties (GZMCRAC et al. 1981; GXZMCRAT 1981; He, J.S. 1981; Xu, H.B. 1981, 1984).

Miziwen Pottery Type was developed on the basis of Kuiwentao Type of Zhou Dynasty. The basic compound of its pottery were the distinctively characteristic stamped pattern pottery urns, pots, Lei wine pots, boxes, $Y u$ basins, jars, cups, and so on, with stamped patterns of Chinese character “米” ( $M i$, the rice)-shaped, checkered, cloud-thunder, and carved water wavy, comb dots, being a basic link in the series of indigenous stamped pattern pottery culture in Pearl River Basin. However, a large number of bronze and iron vessels of this type were mainly Zhou and Chu cultures, including bronze utensils such as tripods Ding vessels with beast-shaped legs, You wine pots, Lei pots, He kettles, Fou (䂐) jars, Jian (鉴) plates, Xi (洗) basins, the bronze musical instruments such as Zhong bells, Zheng (钲) bells, Duo (铎) bells, bronze weapons such as spears, swords, dagger-axes, axes, arrows, sickle, as well as iron axes and shovels, which were identical or similar to those of Zhou, Chu, Wu and Yue cultures. Some bronze and iron artifacts had the characteristic decoration patterns of snake, frog, and Chinese character “王” (Wang, the king), beast or human head masks. These two groups of cultural elements generally continued the external and indigenous groups of cultural contents of Kuiwentao Type, reflecting the cultural continuance, assimilation, and change of Lingnan indigenous society under the influence of Zhou and Chu cultures since the late Warring States Period.

The Checkered and Sealed Pattern Pottery Type was represented by the first category of the burial objects in the tombs of early Western Han Dynasty excavated in Guangzhou, its compound of pottery artifacts were indigenous stamped pattern pottery urns, pots, $B u$ pots, double buttons pots, tripod pots, $F u$ cauldrons, basins, boxes, bowls, buckets, being mainly found in Southern Yue tombs with paved pebbles at the bottom. The second category of the burial objects in Han tombs of Guangzhou was the compound of both the basic pottery of Chu and Han style vessels such as tripod Ding cooking vessels, boxes, kettles, Fang (钫) square kettles, and incense burners in the imitation forms of bronze ritual objects, and the indigenous vessels as the first category, indicating that the immigrated Qin and Han population in Lingnan region and their indigenization in the indigenous Southern Yue society. After the middle and late Western Han Dynasty, the first category of indigenous culture gradually declined and then disappeared, and the second category of mixed Han-Yue compound developed much further, reflecting the continuous expansion of Han culture and the accelerated process of assimilation and sinicization of indigenous Southern Yue society. 


\subsubsection{Overall Stagnancy of Indigenous Social Evolution of Southeast Coast of China Before the Sinicization}

Due to the geographical barrier of Wuyi-Nanling mountains, the hilly region on southeast coast of China was far away from the Huaxia civilization in Central Plains during the Neolithic Age to early Iron Age. Facing and adjacent to the "barbarian" Island $Y i$ in the South Ocean, the sociocultural development of this coastal region receded far behind the plain region lying to the south of the Yangtze River and the civilization "Center" in the middle and lower reaches of Yellow River.

The geographically diverse environment in this mountainous coast region, the warm, humid climate in the tropics and subtropics, and ecological background provided ample food resources with abundant variants and great amount of wild animals, fruits, and edible plants, for indigenous societies with foraging patterns, delaying the emergency and development of productive economy of cereal cultivation for long time in prehistory. From about ten thousand to three thousand years ago, the Neolithic populations settled in caverns, mountainous front slopes, river side terraces of the inland area and the terraces, dunes along the coast and river estuaries in these hilly regions of southeast coast, mainly supported themselves by the foraging patterns of gathering, hunting and fishing for thousands of year (Chang, K.C. 1987b; Wu, C.M. 1996a). The small scale rice farming did not appear until the time of middle and lower layers of Shixia, the middle and upper layers of Niubishan and Tanshishan. Only in the last two or three thousand years ago had rice farming developed into a major source of economic life on limited plots in inland valleys, riverbanks, and coastal plains suitable for farming, receding far behind agriculture developed in the plain region beyond the north and west to Wuyi-Nanling mountain. The Neolithic sociocultural and economic patterns continued and lasted 3000 years ago in the Xia and Shang dynasties when the bronze culture and early civilization in the Central Plain was highly developed (Wu, C.M. 1997b).

The bronze cultures in these regions also appeared and receded later behind the plain region lying to the south of lower reaches of Yangtze River, far behind the Central Plain and North of China. The earliest bronze vessels in the Minjiang River basin were unearthed from the Tieshan Type in the Zhou Dynasty. Neither bronze vessels were found in the Pearl River Basin in the time of Middle Layer Type of Shixia, Hedang (河宕) and middle layer of Jinlanshi (金兰寺) site during the period of the Xia and Shang dynasties, nor did very small amount of bronze vessels were dated earlier than the Zhou Dynasty. Though some bronze vessels unearthed in the Fubin Type in the eastern Guangdong and southern Fujian had the features of bronze vessels of late Shang Dynasty, the general dating of their coexisting artifacts of pottery and other bronzes was also around the Western Zhou Dynasty. The archaeological data proved that this region entirely evolved into the bronze age around three thousand years ago during the Western Zhou Dynasty. Around the Zhou Dynasty, the burial objects in the tombs of Bronze and the early Iron ages included a series of ritual, musical, and weapon vessels with the styles of Central 
Plain and North, such as the bronze tripod Ding cookers, kettles, He wine cookers, Lei wine pots, Zhong bells, dagger-axes, spears, Qi (戚) and Yue (钱) battle-axes, showing the rising of the early local kingdoms such as Min Yue and Southern Yue states (Wu, C.M. 1997b).

\subsection{Island Yi Society: The Continental Connection of the Aboriginal Culture of Taiwan and Hainan Islands}

Hainan, Taiwan, and other continental islands beyond the east and south of mainland China once were the ancient maritime "barbarian" regions of Dan Er, Diao Ti, Island Yi and other maritime ethnicities, where the cultural influence and infiltration from the Central Plain and North were extremely limited along prehistoric and ancient history. The semi-enclosed indigenous cultures developed for a long period in last thousands of years.

The prehistoric and early ancient culture of Hainan island was mainly distributed around its coast of west, south, and southeast. The Neolithic remains have gone through four stages, the earliest was the Yingdun (英墩) remains dating to 60005000 years ago, followed the Lianziwan-Xingjie (莲子湾-新街) remains about 5000 years ago, then the Yinian-Qiaoshan (移劷-桥山) remains about 40003000 years ago, the late stage was the Rongcun-Youba (荣村-右坝) remains dating to 3000-2500 years ago when it still not entered the Metal Age. Each cultural stage shared the same compound of simple material cultures, represented by the round bottom pottery $F u$ cauldrons cookers, pots, bowls, plates, together with usual square type and double shouldered axes and adzes (Qiu, G. 2008; He, G.J. 2012; FSCAT-IA-CASS et al. 2016; Fig. 4.9). This semi-enclosed prehistoric cultural series not only lacked tripod and pouch-shaped leg pottery wares of the Central Plain and North system but also stagnated the ring foot pottery wares that were commonly seen along the southeast coast of mainland China until the quite late period of time. These indigenous cultural series also shared a lot of commonness with the remains of Neolithic Xiantouling and Baojingwan cultures along the coast of Lingnan, showing the same indigenous cultural system of Bai Yue and their interactions across the Qiongzhou (琼州) strait.

The prehistoric cultures of Taiwan centralized on the west coast, and the Neolithic cultures developed temporally in early, middle, and late stages. The early stage was Tapenkeng (大贫坑) Culture (5500-4200 BP), varying spatially with the early stage of Xuntangpu (讯塘埔) Culture in the north, the early stage of Niumatou (牛骂头) Culture in the central and Guoye (菓叶) Type in the south. The middle stage (4200-3200 BP) also varied with three district types, they were the late stage of Xuntangpu Culture in the north, the late stage of Niumatou Culture in the central, and the Niuchouzi (牛稠子) Culture in the south. At the late stage (3200-1800 BP) were Yuanshan (圆山)-Botanical Garden (植物园) Culture in the north, Yingpu 


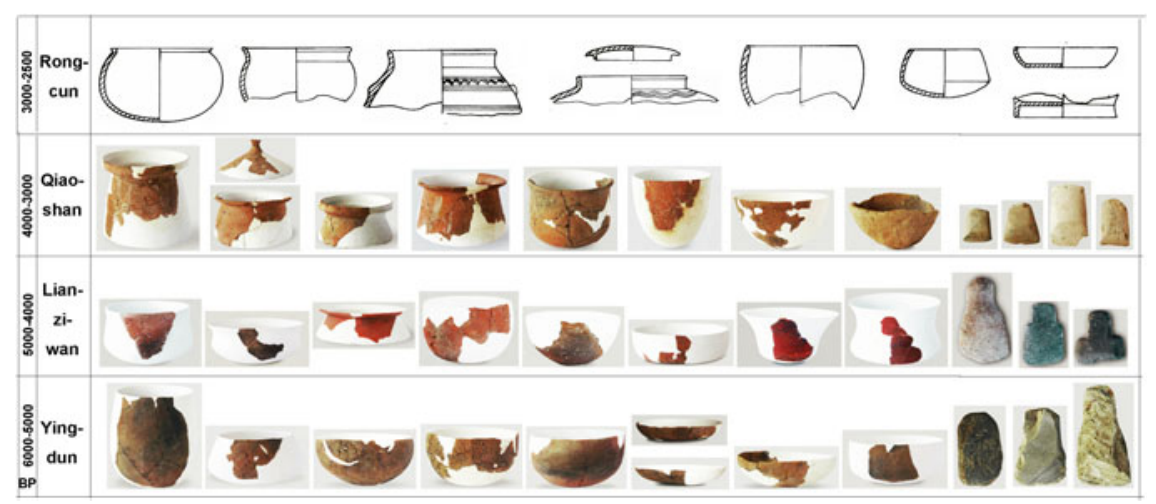

Fig. 4.9 The material cultural sequence of Neolithic Hainan Island

(营埔) Culture in the central and Tahu (大湖) Culture in the south. Closely following these Neolithic cultures were the regional variants of the Iron Age (1800400 BP), including Shisanhang (十三行) Culture in the north, Fanzaiyuan (番仔园) Culture in the central and Niaoshong (茴菘) Culture in the south (Chang, K.C. 1969, 1987a, 1989; Han, Q. 1979; Li, J.T. et al. 1992; Tsang, C.H. 1999; Tsang, C. H. et al. 2013; Kuo, S.C. 2019; Fig. 4.10).

In the early Neolithic stage, the Tapenkeng Culture was mainly characteristic of sandy red pottery with stamped coarse corded patterns, carved, incised and nail engraved patterns, and the main vessel types were the high neck pots and bowls with round bottom. Tripod pottery wares were not found. The style of high neck globular belly and round bottom pots with circular ridged on neck was similar to the remains at Xiantouling, Dawan, Guye, Zengpiyan, Shiweishan-Fuguodun, and Keqiutou in the early Neolithic stage of Fujian and Guangdong. However, the dating of the Dapengkeng Culture was about 5000-2000 years respectively receding behind the same stage of Neolithic culture in the southeast coast of the mainland (Li, J.T. et al. 1992).

The cultures of late stage of the Xuntangpu, the late stage of Niumatou and Niuchouzi in the middle Neolithic stage were respectively similar to the remains in the lowest deposit remains of Shixia, lower layer of Jinlanshi and the Lower Layer Type of Tanshishan, in particular, their representative characteristics of polished red pottery, fine corded pattern pottery, red painting geometric pattern pottery, with the types of narrow neck and round bottom pots, $F u$ cauldrons cookers, straight high neck ring foot kettles, were very consistent. However, the dating of these spatial types of middle stage Neolithic culture on the west coast of Taiwan also receded about 3000-2000 years behind the same stage of those red pottery cultures on the coast of Fujian and Guangdong (Li, J.T. et al. 1992).

The remains of grey and black pottery in Yuanshan, Yingpu, and Tahu cultures in the late Neolithic stage were similar to those of Hedang, Shixia Cultures, and the Middle Layer Culture of Tanshishan along the mainland southeast coast in the 


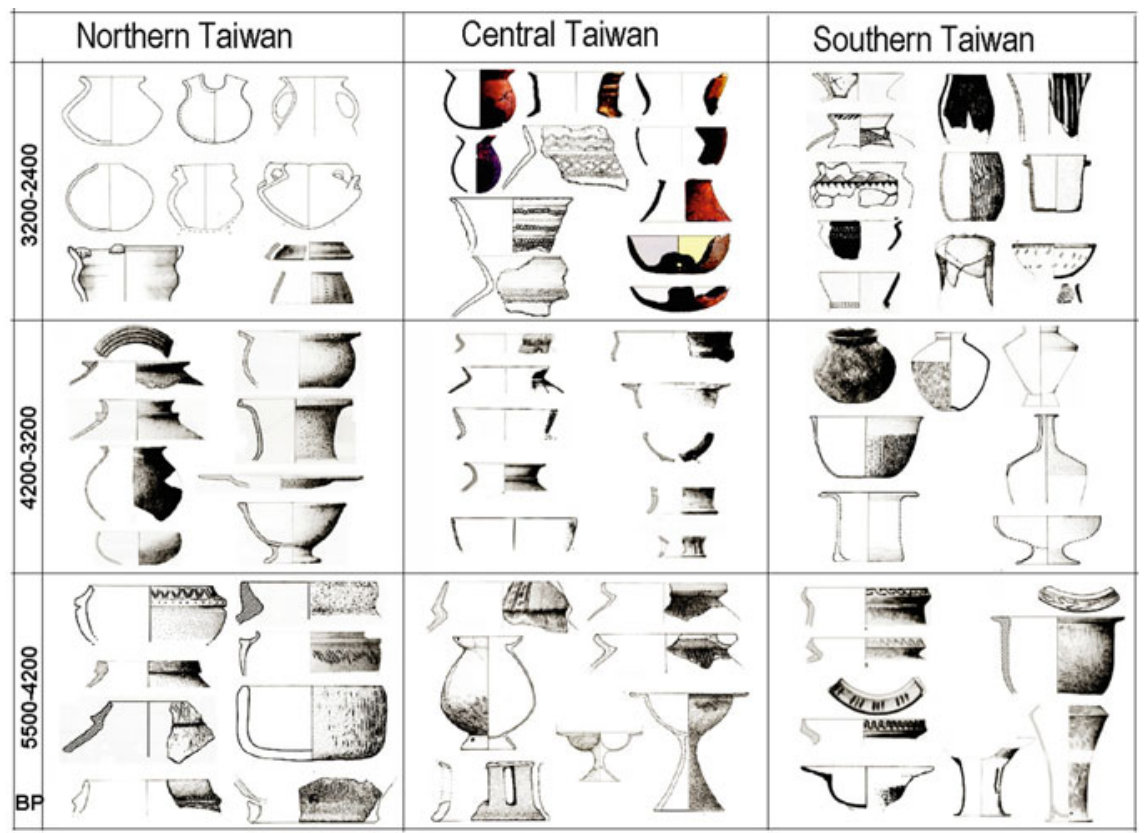

Fig. 4.10 The Neolithic cultural sequence in western coast of Taiwan (After Kuo, S.C. 2019)

Longshan period. The late Neolithic cultures in Taiwan also receded more than 1000 years behind the same stage of Fujian and Guangdong (Li, J.T. et al. 1992).

In spite of the acceleration of the cultural unification and assimilation of Han culture in the "Southeastern Direction" of mainland China for more than two thousand years, the main body of Taiwan ethnicities remained its indigenous identity of Iron Age in the long historical period. Judging from the material cultural heritage of the primitive pottery making of Taiwan Aboriginal Gaoshan ethnicity (高山族) lasting to the modern period, it inherited and continued in line with the indigenous cultural tradition of the stamped geometric pattern pottery in Fujian, Guangdong, and Taiwan from the Neolithic to early Iron ages (Wu, C.M. 1994b; Fig. 4.11).

\subsection{Conclusion}

The preliminary synthesis on the prehistoric cultural chronology and typology from the Neolithic to early Iron ages in the southeast of China, reveals that the common features of the stamped pattern pottery remains of variedly spatial and temporal types represent a regional indigenous cultural unity different from the cultural system of Central Plain in the middle and lower reaches of the Yellow River. These 


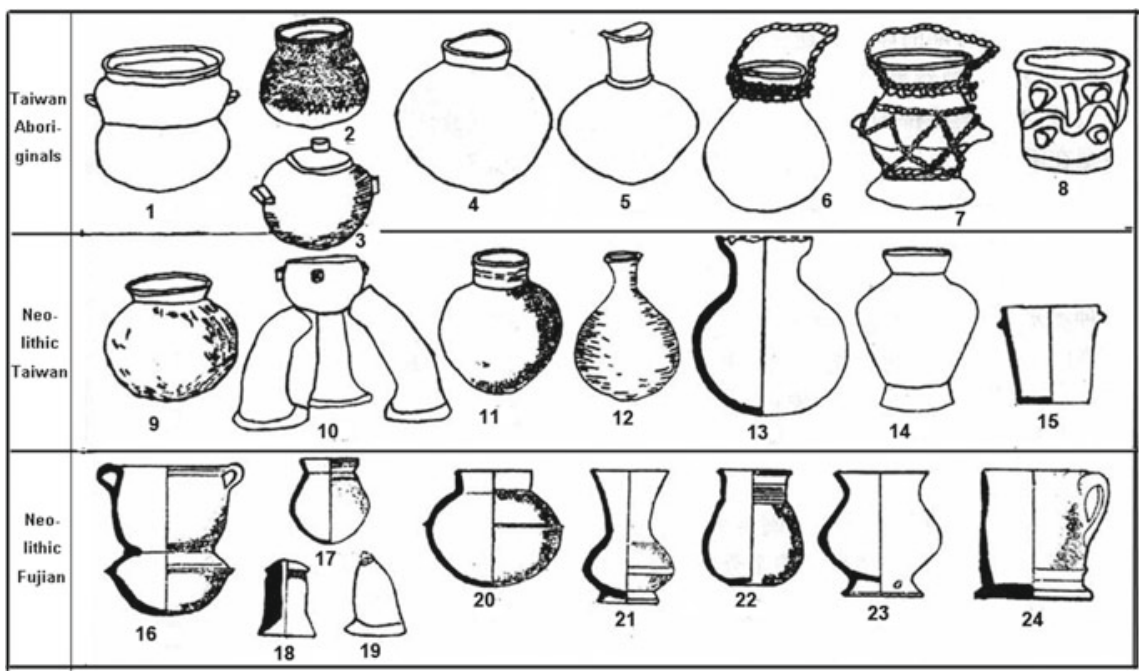

Fig. 4.11 A comparison of Neolithic and indigenous potteries of Fujian and Taiwan (1-8. Indigenous potteries of modern Taiwan; 9. Kending 层丁; 10. Niaosong 鸟崧; 11, 13. Nantou 南 投; 12. Hualian 花莲; 14. Fengbitou 凤鼻头; 16, 24. Huangtulun 黄土仓; 17-18. Keqiutou 壳丘 头; 19. Tanshishan 昙石山; 20 . Zhuangbianshan 庄边山; 21,23 . Xitou 溪头; 22. Baizhuduan 白 主段)

archaeological types are the cultural heritage of the indigenous ethnicities of Miao, Man and Bai Yue in different stages on the "Southeastern Direction" of Central Nation, and an integral part of a wider and trans-boundary indigenous cultural system of "Maritime Region of Southeastern Asia". Due to the geographical barrier of mountains and seas, the different distances and locations in the geopolitical order of Center-Periphery in ancient Chinese civilization, these indigenous cultural types from Neolithic to early Iron ages obviously varied in series of spatial and temporal diversity, with three different sociocultural regions, namely the plain region lying to the south of the Yangtze River relying on Huaxia nationality and territorially connecting to the Central Plain, the hilly region along the southeast coast facing and connecting the maritime "barbarian" of Islands $Y i$ and Austronesian in South Sea (Ocean), and the oceanic region of Taiwan and Hainan islands as a part of maritime island "barbarians" in broader Asia-Pacific region.

This indigenous cultural system with spatial and temporal variants of three regions and a number of sub-regions, presented differentially cultural interaction with the Huaxia system in Central Nation and maritime "barbarians" including Austronesian of the South Sea (Ocean). On the one hand, "Relying on Huaxia Nationality" in the ancient Chinese civilization characterized by the unity of the "Assimilation and Integration of Pluralistic Cultures" and the geopolitical order of "Central Nation-Various States in Four Directions-Gullied Boundary of the Four Seas", the variant of cultures in three regions were respectively influenced and assimilated in varying degrees, directly or indirectly by the Huaxia system. This 
influence and assimilation had been continuously strengthened from the south to north, and the indigenous societies in mainland southeast had been generally assimilated into the Han culture system up to the time of Qin and Han dynasties. On the other hand, "Facing and Connecting the Islands Yi and Austronesian", the indigenous cultural features respectively in these three regions were gradually strengthened from the north to the south, from land to sea. In particular, the semi-enclosed situation, the indigenous culture connotation, the foraging patterns of gathering, fishing, and hunting economy, and the pre-state society of the Neolithic to early Iron cultures in coast region beyond the south and east of Wuyi-Nanling watershed, had continued and stagnated for a long period of time. The prehistoric and early cultures of this coast region had also been closely connected and interacted with the Island $Y i$, which is the important source for searching the origin of Austronesian in the "Maritime Region of Southeastern Asia".

Open Access This chapter is licensed under the terms of the Creative Commons Attribution 4.0 International License (http://creativecommons.org/licenses/by/4.0/), which permits use, sharing, adaptation, distribution, and reproduction in any medium or format, as long as you give appropriate credit to the original author(s) and the source, provide a link to the Creative Commons license, and indicate if changes were made.

The images or other third party material in this chapter are included in the chapter's Creative Commons license unless indicated otherwise in a credit line to the material. If material is not included in the chapter's Creative Commons license and your intended use is not permitted by statutory regulation or exceeds the permitted use, you will need to obtain permission directly from the copyright holder.

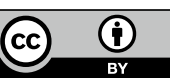

